\title{
Vignola em Português: anotações a partir das Regras das Cinco Ordens de $1787^{1}$
}

\author{
Angela Brandão*
}

\begin{abstract}
Resumo Este texto trata da difusão dos Tratados de Arquiteutra do Renascimento, em especial de Giacommo Barozzi da Vignola: Regole delle cinque ordine dell'Architettura (1572). Tal difusão como literatura aristocrática; como conhecimento erudito de arquitetos nas Academias; mas também como saber adaptado ao mundo dos artesãos, exigido para exames de ofício, de acordo com o Livro dos Regimentos dos Oficiais Mecânicos, compilado em Lisboa (1576). Desde o século XVII, as edições de Vignola indicam diferentes utilizações deste conhecimento, sendo que no XVIII adquire um sentido de resgate do Antigo, em detrimento das invenções do Barroco e Rococó. Nesse contexto surgem as duas primeiras edições portuguesas de Vignola.
\end{abstract}

Palavras-chave: Vignola, Tratados, artesãos.

\section{Vignola en Portugués: apuntes a partir de las Reglas de los Cinco Órdenes de 1787}

\begin{abstract}
Resumen Este texto trata de la difusión de Tratados de Architectura del Renacimiento, sobre todo el de Giacommo Barozzi da Vignola: Regole delle cinque ordine dell'Architettura, 1572. Tal difusión como literatura aristocrática; conocimiento erudito por parte de arquitectos en las Academias; fue también un saber adaptado al mundo de los artesanos y exigido para los exámenes, de acuerdo con el Libro de las Ordenazas de los Artesanos, escrito en Lisboa (1576). Desde el siglo XVII, ediciones de Vignola indican distintas utilizaciones de este conocimiento, y en el XVIII adquiere un nuevo sentido de recuperación mas fiel de la Antiguedad, en oposición a las invenciones del Barroco y Rococó. En este contexto surgen, en 1787, dos primeras ediciones portuguesas.
\end{abstract}

Palabras clave: Vignola, Tratados, artesanos.

\section{Vignola in Portuguese: notes on the Rules of the Five Orders from 1787}

Abstract This text deals with the diffusion of Renaissance Architectural Treaties, mainly that one by Giacommo Barozzi da Vignola: Regole delle cinque ordine dell'Architettura (1572). Such diffusion as aristocratic literature; as a scholarly knowledge held by architects in the Academies; was either a knowledge adapted to artisans and required for their examinations, according to the Livro dos Regimentos dos Oficiais Mecânicos, (Lisbon, 1576). Since the seventeenth century numerous editions of Vignola indicated different uses of this knowledge. In the eighteenth it acquires a sense of redemption of the Antique in opposition to the inventions of Baroque and Rococo. In this context, appeared the first two Portuguese editions of Vignola.

Keywords: Vignola, Treaties, artisans. 


\section{Livro dos Regimentos}

No contexto português, a matéria exigida pelos exames de ofício, para que um oficial não examinado ou aprendiz se tornasse um artesão no sentido pleno, assim como todas as demais regras para o exercício das profissões artesanais, foram compiladas no Livro dos Regimentos da Mui nobre e sëpre leal cidade de Lisboa em 1576. O Livro dos Regimentos resultava de normas consuetudinárias que demarcavam os trabalhos das corporações de ofício desde a Idade Média portuguesa. Tais preceitos foram aplicados no Brasil Colonial, certamente com uma série de limites e modificações até o início do século XIX.

Se um artesão quisesse examinar-se, não bastava o domínio técnico de seu ofício, era preciso conhecer a matéria presente nos Tratados Artísticos do Renascimento Italiano. Os Regimentos permitem ver, a partir das exigências às quais deveriam se submeter os examinados, o grau esperando de conhecimento teórico dos cânones clássicos transmitidos através dos tratados arquitetônicos, que circulavam no mundo ibérico desde o século XVI, influenciando a arte, suas práticas e seus preceitos (MOREIRA E RODRIGUES, 2011; BRANDÃO, 2014: 429-436).

O exame dos pedreiros exigia que o artesão realizasse, entre outras peças, uma coluna dórica com sua base e capitel. Os ensambladores fariam um painel de sete palmos de altura e cinco palmos de largura, com sua moldura, (...) e depois, este painel deveria ser decorado com colunas dóricas, torneadas, bem proporcionadas e, sobre as colunas, tinha de fazer um friso, com seus tríglifos, sua arquitrave e frontispício com proporções adequadas" (CORREIA, 1926: 105. 110). Elementos como esses indicavam a necessidade de conhecimento das ordens clássicas, colunas e frontispícios, seus valores e suas proporções.

Para o exame de entalhador, o artesão teria que realizar um friso com ornamentos romanos, muito bem ordenados e, no centro: "(...) Fará um capitel coríntio de um palmo de diâmetro e a altura será proporcionada a esta divisão, o capitel será ornado de folhas e caulículos muito bem feitos (...) na ordem das folhas e disposição de todo o ornamento deste capitel guardará as obrigações coríntias(...)" (CORREIA, 1926: 111).

* Angela Brandão é Historiadora, Professora da Escola de Filosofia, Letras e Ciências Humanas, da Universidade Federal de São Paulo, campus Guarulhos, ORCID $<$ https://orcid.org/0000-00018946-9910>.
Os exames indicavam, portanto, as aproximações entre os trabalhos artesanais, cujos conhecimentos eram transmitidos predominantemente de forma oral; e a produção de peças detentoras de princípios artísticos eruditos, baseados em livros escritos. Já o Regimento do Officio de Carpinteiro de Moveis e Semblage, publicado em Lisboa em 1767, determinava para o exame: "um retábulo de sete palmos ou como the determinar os juízes o qual levará suas colunas e será feito dentro do preceito da Arquitetura [grifo nosso], ordenando os juízes de qualquer das cinco ordens, e desta ha de fazer a obra de exame" (TOLEDO, 1996)². 
1 Esta pesquisa contou com Bolsa de Produtividade em Pesquisa CNPq2 (processo 306646/20170) e Auxílio Regular FAPESP (processo 2017/20984-6).

2 Regimento do Officio de Carpinteiro de Moveis e Semblage. Arquivo da câmara de lisboa (ref. Bl 2a 32.03.38).

\section{Tratados de Arquitetura e sua difusão no ambiente dos artesãos}

Parece haver, portanto, desde os Regimentos de 1572, uma clara referência aos tratados de Arquitetura como o de Giacomo Barozzi da Vignola (1508-1573), Regole delle cinque ordine dell'Architettura (1562), que exerceu enorme influência sobre o mundo ibérico. É importante, no entanto, averiguar uma possível presença de tratados "menores" que "simplificaram" ou "vulgarizaram" o conhecimento dos "grandes" tratados, tornando-os mais adequados a ambientes como os ateliês de carpinteiros e marceneiros. Em oposição a uma literatura aristocrática, por assim dizer, dos Tratados Artísticos, produzida e lida em ambientes das Cortes, Julius von Schlosser (2000: 411-413) evocou uma literatura dos tratados, limitada ao ambiente artesão e pequeno burguês, como libretos populares sobre as cinco ordens, os chamados Säulenbuchlein, como, por exemplo, o livro de Hans Blum, Buch von den fünff sülen (Livro dos Cinco Pilares), editado em latim, em Zurique em 1550 e em alemão em 1554. Um dos últimos escritos desse tipo, segundo Schlosser, foi publicado por um ebanista austríaco, justamente um marceneiro especializado, Johann Indau, editado por primeira vez em 1686. Julius von Schlosser (2000: 418) considerou ter havido, de fato, uma absorção ingênua de Vignola também ao norte da Itália, a partir do século XVII, como um "catecismo", especialmente para as artes decorativas.

Esta "absorção ingênua" (para usar as palavras de Schlosser) do conhecimento dos tratados, por ebanistas diletantes e outros artesãos, deu-se, portanto, não apenas por leituras "simplificadas" de Vignola, mas por meio de diversos livros tais quais os de Blum ou Indau, referidos por Schlosser (2000: 418), ou como o L'Architectura, do chamado "Vitruvio Flamengo", Vredeman de Vries (1527-1609), nos Países Baixos. Esse processo de tradução do conhecimento dos tratados de arquitetura para o mundo dos artesãos levaria à construção em pequenas dimensões de templos domésticos: lareiras, móveis e outros elementos de decoração interna com aspecto monumental, como arquiteturas em miniatura.

Para Jaime Souza (1989: 298), com efeito, desde o século XVII, os trabalhos de marcenaria também em Portugal passaram a ser "objeto de um olhar mais consciente e atento", num "processo de autonomização" do mobiliário "que culminará no século XVIII". Jaime Souza propôs justamente a hipótese de circulação, entre os marceneiros portugueses, de tratados como os de Vredeman de Vries. Isso teria permitido a consciência e autonomia de objetos como os móveis, transformados em "obras de arte".

O tratado de Vredeman Vries, Architectura (1527) foi importante para o conhecimento das ordens arquitetônicas nos Países Baixos no final do século XVI e começo do XVII, pois permitiu uma adaptação do conhecimento dos Tratados italianos de Arquitetura ao universo dos artesãos, uma vez que o próprio texto e suas ilustrações indicavam as características das ordens adequadas aos diversos tipos de construção, incluindo lareiras, por exemplo. Não poderíamos afirmar, no entanto, que o tratado de Vredeman de Vries tenha sido tão somente uma simplificação ou uma vulgarização de Vitrúvio ou de Serlio, tampouco apenas a passagem de um conhecimento intelectual para uma dinâmica prática. Tratava-se da passagem do modo como se pensava a arte na Itália, a partir do Renascimento, para um contexto artístico diferente, tanto na Holanda, segundo Svetlana Alpers (1984: 24) - como em Portugal. 
3 VREDEMAN DE VRIES, Hans. ARCHITECTURA, ou Bâtiment, pris de Vitruve et des anciens écrivains, Traitant sur les cinq ordres des colonnes, dont on peut ordiner et approprier toutes sortes et pratiques des bâtiments, profitable pour tous maîtres de fabrique, maîtres maçons, menuisiers, charpentiers, tailleurs $d^{\prime}$ images et tous autres amateurs de l'art d'architecture, avec la déclaration des figures, de nouveau mises en lumière et inventées par Jean Vredeman, 1527. Disponível em Archive <https://archive.org/ details/gri_33125009324910>, acesso em 21 de agosto de 2017.

4No original em latim: Perspective, id est, Celeberrima ars inspicientis aut transpicientis oculorum aciei in pariete, tabula aut tela depicta, in qua demonstrantur quaedam tam antiqua, quam nova aedificia, templorum, sive aedium, aularum, cubicularum, ambulaciorum, platearum, xystorum, hortorum, fororum, viarum et hujusmodi alia, quae nituntur suis fondamentalibus lineis, quorum fondamentum descriptionibus clare exsplicatur, perutilis ac necessaria, omnibus pictoribus, sculptoribus, statuariis, fabriferrariis, architectis, inventoribus, cæmentariis, scrinariis, fabrilignariis, \& omnibus artium amatoribus, qui huic arti operam dare volent, majori cum voluptate, \& minori cum labore. VREDEMAN DE VRIES, Hans (1527-ca 1606). Perspective. French text. Leyden and the Hague: Beuckel Nieulandt for Hendrik Hondius, 1604-1605. Disponível em Archive. https://archive.org/details/ gri_33125009324910, acesso em 21 de agosto de 2017.

5 Ver SILVA, Mônica Messias. Antiguidade da Arte da Pintura, sua nobreza, divino e humano que a exercitou, e honras que os monarcas fizeram a seus artífices Félix da Costa Meesen - 1696 Texto Modernizado e Análises. Dissertação. Programa de Pós-Graduação "Culturas e Identidades Brasileiras". Instituto de Estudos Brasileiros (USP-São Paulo), Orientador: Prof. Dr. Luiz Armando Bagolin. São Paulo, 2018. Disponível em $<$ https://teses.usp.br/teses/disponiveis/31/31131/tde-01032018130721/publico/Corrigida_MonicaSilva.pdf>. Acesso em 22 de outubro de 2019.
De qualquer forma, a difusão de livros como os de Vries no ambiente dos artesãos, indicava a aplicabilidade do princípio da perspectiva e das Ordens Clássicas à talha, ao mobiliário, às lareiras, à tapeçaria e a objetos de madeira de pequenas dimensões. Tais edições, de modo geral, passaram a ser considerada como um saber que transitava entre as artes e as ciências, aplicado às artes decorativas. Não haveria, nessas obras, uma separação hierárquica entre as artes "maiores" e as artes aplicadas, como tampouco entre o saber prático e o saber teórico, aglutinando os conhecimentos da engenharia à hidráulica, da marcenaria à tapeçaria (LOMBAERTE, 2005; BRANDÃO, 2017).

Ao introduzir seu livro Architectura (1527), o próprio Vries prescrevia, já no título, o uso desta "ciência" para todas as artes, incluindo as "menores".

Arquitetura ou construção, tomada de Vitrúvio e dos antigos escritores, tratando sobre as cinco ordens das colunas, das quais se pode ordenar e apropriar todo os tipos e práticas das construções, aproveitável para todos mestres de obras, mestres pedreiros, marceneiros, carpinteiros, entalhadores de imagens [grifo nosso] e todos os outros amadores (amantes) da arte da arquitetura,(...). (VREDEMAN DE VRIES, 1526) 3

O conhecimento e a capacidade de aplicar as Cinco Ordens Clássicas estaria certamente combinado ao domínio do desenho e da perspectiva, compreendidos de maneira ampla pelo tratadista holandês. Parafraseando a introdução de seu Livro da Perspectiva (1604-1605) [figura 1] vemos que a perspectiva era, para ele, uma "celebérrima arte de observação e perspicácia visual", muito útil e necessária, tanto aos pintores, escultores, entalhadores, ferreiros e arquitetos e inventores, pedreiros e construtores, cenógrafos, marceneiros, e em todas as artes de todos os amadores, para dar uma maior sensação de prazer, com o menor esforço².

Essas palavras se assemelhavam a um dos primeiros tratados artísticos redigidos em língua portuguesa, de Félix da Costa, Antiguidade da Arte da Pintura (1685-1688), que defendia a importância do desenho:

Couza $m^{\text {to }}$. Necessaria aos Pintores, Escultores e Arquitectos; porque todas estas tres Artes requerem $m^{\text {to }}$ Debuxo... M. ${ }^{\text {to }}$ conveninte aos Engenheiros... Aos ourives do Ouro e da Prata muy necessario,(... ) Parte essecial aos Entalhadores, para fazerem o relevo de talha com propriedade, e inventarem com graça e sciencia as fabricas dos retabolos.... (...) Aos Marceneiros, pa fazerem os Contadores, Leitos, bufetes, e mais com boa invenção; entenderem bem as plantas e riscos de outrem, e fazerem elles mesmos boas invenções e riscos... E não há Arte nem ofício, q em todo ou em parte não dependa da Arte do Debuxo ${ }^{5}$. (DA COSTA, apud CARVALHO, 1977: 43)

A obra de Vries era baseada especialmente em Vitrúvio e Serlio. As Regras das Cinco Ordens de Arquitetura, de Vignola, foi, contudo, o livro do gênero que obteve o maior sucesso editorial, segundo Schlosser (2000: 410-413, 421-422), suplantando a fama de Serlio já na primeira metade do século XVII e também superando, em muito, os grandes tratados de Palladio e Scamozzi. Isso se deveu, talvez, a sua forma sóbria e acessível, recomendado como livro didático, infinitas vezes reeditado, traduzido e transcrito em todas as línguas e lugares. O livro de Vignola se tornou, definitivamente, o manual do estudante e diletante em arquitetura por séculos. As Regras consistem 
Figura 1: VREDEMAN DE VRIES, Hans (1527-ca 1606). Perspective. Edição francesa. Leyden and the Hague: Beuckel Nieulandt for Hendrik Hondius, $1604-$ 1605. Fonte: Disponível em Archive <https://archive.org/details/ gri_33125009324910>
6 "For de use and benefit of Free Masons, Carpenters, Joyners, Carvers, Painters, Bricklayers, Plaisterers". The Translators Preface. To the Reader. The Regular Architect or the General Rule of the Five Orders of Architecture of M. Giacomo Barozzio da Vignola... By John Leeke. Printed by W. Sherwing. London, 1669.

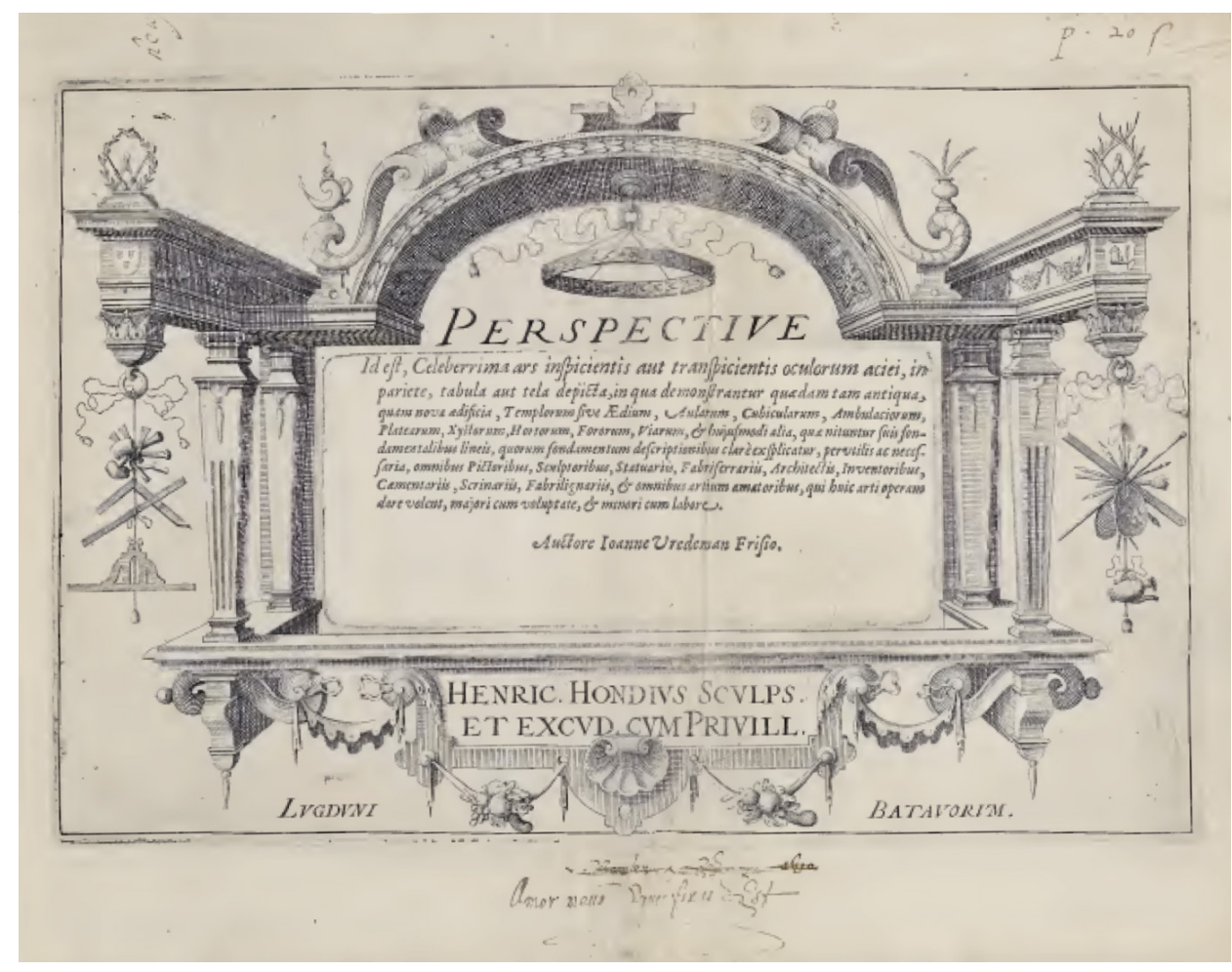

num livro didático, segundo Schlosser, tanto no bom quanto no mal sentido: ideias claras, sóbrias, objetivas, bem dispostas, mas feitas de fórmulas. Entram sem rodeios no tema das cinco ordens como um "abc" de toda vera arquitetura e, pela primeira vez, este livro fundou o dogma do sistema das Cinco Ordens, em grande parte arbitrário e anti-histórico ou supratempral.

A primeira tradução de Vignola para o inglês foi realizada por John Leek em 1669. Uma das principais preocupações da tradução de Vignola por Leeke (2011) era educar na linguagem clássica os construtores, autores de risco e artesãos que eram requisitados para reconstruir Londres depois do grande incêndio de 1666: "Para o uso de pedreiros livres, carpinteiros, ensambladores ou marceneiros, entalhadores, pintores, construtores e estucadores". Sua intenção era apresentar o livro como um auxiliar para o trabalho prático e não como um livro teórico, como atesta sua dedicatória aos leitores, onde diz que os autores sobre arquitetura proporcionam muitas descrições e explicações sobre os ornamentos das cinco ordens. Ao estabelecer o cânone tomado do antigo para reduzi-lo às cinco ordens, Leeke (como Vignola) "facilitou-o" ainda mais para ser colocado em prática na reconstrução de Londres, para que todos pudessem compreendê-lo e retê-lo facilmente na memória ${ }^{6}$.

A obra Règles des cinq ordres d'architecture de Vignole foi editada em 1691 e 1694 por François Jollain (ca. 1641 - 18 April 1704), gravador de cobre que pertencia a uma família de gravadores de Paris. As Règles de Jollain consistiam igualmente em exemplo de edições francesas simplificadas de Vignola. Embora muitas edições de Vignola do século XVII se voltavam a leitores que pretendiam uma leitura mais "prática", 
7 Jacques-François Blondel foi professor de arquitetura, recusado pela Académie Royale d'Architecture, abriu uma escola particular de arquitetura, l'École des Arts (1743) que foi fechada duas vezes, sendo reaberta em 1747 e 1754, e tendo entrado em falência em 1754. Finalmente aceito na Académie royale d'architecture em 1755, Jacques-François Blondel se tornou professor a partir de 1762. (DURANTE, 2015) digamos, das Ordens, ocorre também uma "aplicação de Vignola" como guia para a formação acadêmica dos arquitetos no contexto francês por autores como Charles Augustin D'Aviler (1653-1700) em seu Cours d'Architecture qui comprend les Ordres de Vignole, de 1691, editado no mesmo ano da impressão de Jollain, mas com várias edições sucessivas que iriam até 1696 . Aqui as Ordens Clássicas passavam a fazer parte de um sistema de controle total da arquitetura, das artes e das manufaturas, pelo projeto absolutista de Colbert para Luís XIV.

Se para autores como John Leek $(1669)$ e François Jollain $(1691,1694)$ a utilização do conhecimento advindo dos tratados se dirigia sobretudo aos trabalhadores manuais, por sua vez, o Cour d'Architecture de Charles D'Avilier (1691-1696) devolvia, ao contrário, Vignola a uma leitura da Academia e para os arquitetos, ao final do século XVII. Então, seria um equívoco afirmar que as edições e adaptações de Vignola no século XVII tenham sido voltadas exclusivamente para a transposição de um conhecimento erudito e acadêmico da arquitetura para as artes menores e para o ambiente da oralidade dos artesãos. Ao contrário, parece ser mantida a ambiguidade com relação à absorção de Vignola que Schlosser (2000) pretendia revelar.

A circulação dos tratados consistiu, com efeito, já no século XVII europeu, numa rede de conhecimentos que ultrapassou fronteiras geográficas e linguísticas, uma vez que tais textos foram traduzidos para diferentes idiomas e, muitas vezes, em várias línguas concomitantemente. Esta rede perpassou o universo do conhecimento aplicado aos trabalhos artesanais desde a segunda metade do século XVI e no percurso dos séculos XVII e XVIII.

\section{Vignola no século XVIII}

Qual o destino de Vignola no Século XVIII? Caberia, para compreender as inúmeras edições, transcrições e adaptações de Vignola fazer uso da teoria da tradução (CATFORD, 1980)? A incrível versatilidade e maleabilidade com que se aplicou o conhecimento das Ordens Clássicas advindas de Vignola pode ser notada num livro como o de Jacques François Blondel (1705-74). Livre Nouveau ou Règles des Cinq Ordres d'Architecture, Paris 1757. Esta edição é ilustrada com elementos de decoração rococó, onde personagens em miniatura em cenas cotidianas passeiam e se acomodam entre as colunas de Vignola ${ }^{7}$ [figura 2]. Isso demonstra a liberdade com a qual Vignola era reinventado por sucessivas traduções, edições e reinterpretações - como uma "obra aberta".

No entanto, no mesmo século XVIII, a utilização do modelo de Vignola parece atender, por outro lado, à necessidade de retorno ao clássico e de "correção das deformações" que a arquitetura teria sofrido ao longo do período barroco e rococó. No setecentos, ocorreu o interesse renovado por parte do olhar neoclássico em direção à Antiguidade: suas medidas exatas; o conhecimento preciso pelo olhar arqueológico-científico e seus elementos emblemáticos, entre os quais especialmente as colunas e as Ordens Clássicas (RYKWERT, 2015: 14).

Giuseppe Maria Ercolani, padre italiano estudioso da arquitetura, de origem nobre, publicou em 1744 "I tre ordine d'architettura dorico, ionico e corintio presi dalle fabbriche più celebri dell'antica Roma" [figura 3]. Não trazia uma edição de Vignola, mas apresentava a 
Figura 2 (topo): BLONDEL, Jacques François. Fonte: Livre Nouveau ou Règles des Cinq Ordres d'Architecture, Paris 1757.

Figura 3: ERCOLANI, Giuseppe Maria. I tre ordine d'architettura dorico, ionico e corintio presi dalle fabbriche più celebri dell'antica Roma. Fonte: Roma: Antonio de Rossi, 1774. Biblioteca da Scuola Normale Superiore di Pisa, Itália.

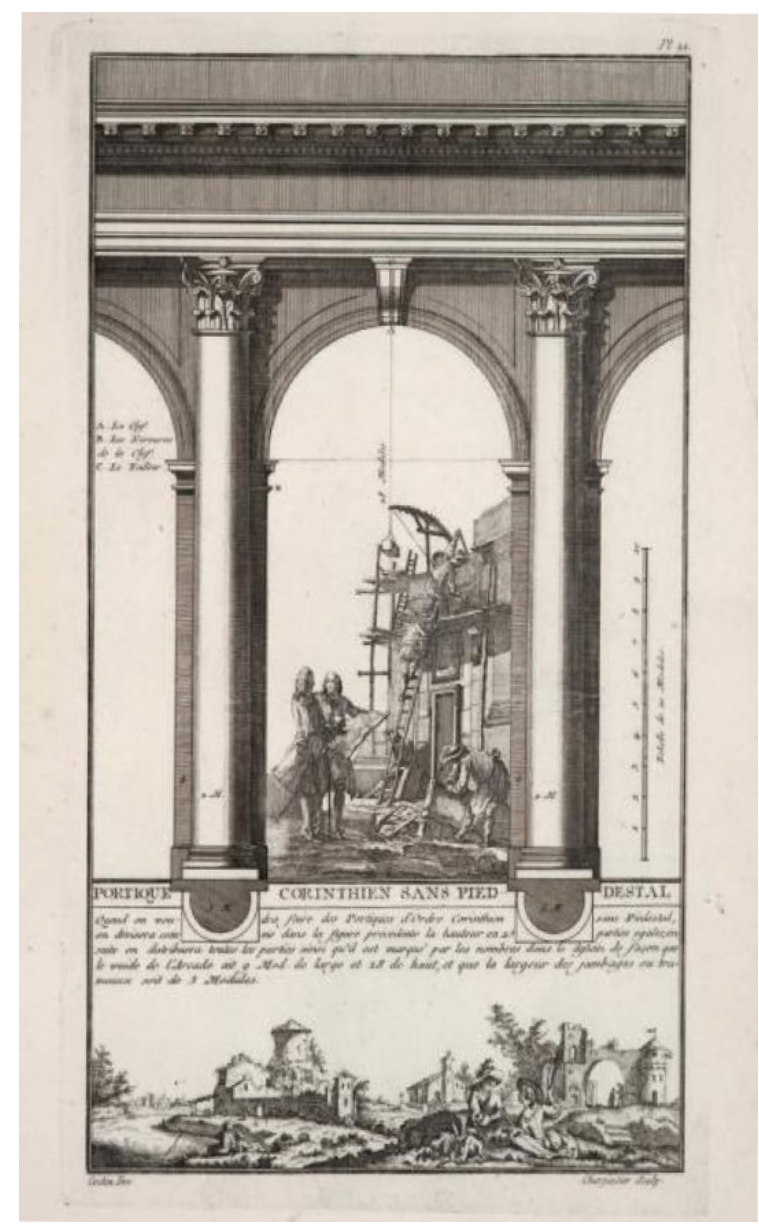

I T R E O R D I N I

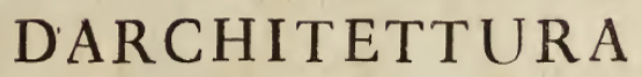
DORICO, JONICO, E CORINTIO

Prefi dalle Fabbricbe più celebri dell' Antica Roma, e pofti in ufo con un nuovo efattifimo metodo.

O PER A

D I NER A L C O P. A.

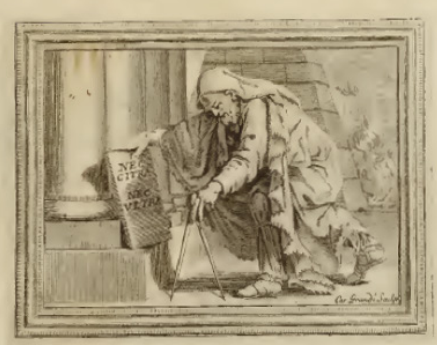

I N R O M A MDCCXLIV.

Nella Stamperia di Antonio de' Rossi.

CON LICENZA DE SUPERIORI. 
8 Essas edições foram tratadas por Marcos Tognon numa conferência de 2014, "Tratados De Arquitetura no Século XVIII para a Produção Artística Barroca: O "Vinhola Português " do Século XVIII".

Figura 4: BINHETI, José Carlos. Regra das cinco ordes de Architectura de Jacomo Barocio de Vinhola traduzidas do seu original em nosso idioma com hum acrescentamento de Geometria Pratica, e Regras de Prespectiva de Fernando Gallibibiena. Lisboa, José de Aquino Bulhões, 1787. Fonte: Setor de Microfilmes da Biblioteca Nacional de Portugal. tentativa de restituir um certo purismo perdido das Ordens Clássicas. Inicia o livro com as seguintes palavras: "vendo cada vez mais a desordem da Verdadeira Antiga Arquitetura por tantas licenças, com as quais a deformaram não poucos modernos professores, decidi escrever o presente Tratado para reparar, se for possível, seu deplorável abuso." Vignola continuará a ser evocado no século XVIII como um caminho de recuperação do clássico, que se estava perdendo diante dos abusos de invenção barroca e rococó.

Três anos depois da edição italiana de Ercolani, é publicado na França o livro Jacques Barozzio de Vignole. Nouveau Livre, com gravuras de Babel, editado por Jacques Cherreau (1747). Em 1786, sai em Paris, mais uma edição de Vignola, desta vez as Règles des Cinques Ordres de l'Architecture de Vignole de Claude-Mathieu Delagardette, arquiteto e aluno da Academie Royale d'Architecture de França, como uma edição decididamente neoclássica, o que se pode notar mesmo pela forma gráfica do livro.

\section{Vignola em Português}

Em meio às edições deste novo contexto setecentista, que atualizavam a seu modo e reforçavam o propósito de leitura dos Tratados de Arquitetura e a difusão da didática das "Ordens", vêm à luz duas publicações em Portugal de Vignola, ambas editadas em $1787^{8}$, ou seja, um ano depois do livro de Delagardette (1747). Uma dessas edições, do arquiteto decorador de origem italiana, nascido em Lisboa, José Carlos Binheti, foi impressa em Lisboa com o título: Regra das cinco ordes de Architectura de Jacomo Barocio de Vinhola traduzidas do seu original em nosso idioma com hum acrescentamento de Geometria Pratica, e Regras de Prespectiva de Fernando Gallibibiena [figura 4]. José Carlos Binheti (1787) afirmava, na exposição ao leitor, que o motivo

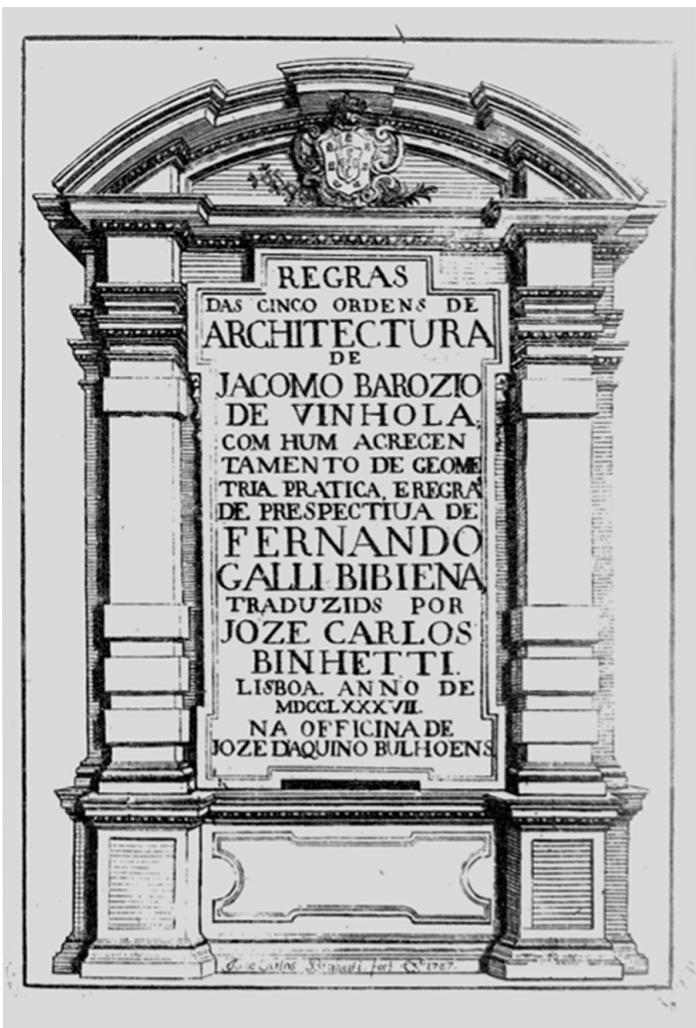


Figura 5: J.C.M.A Regras das Sinco Ordens da Architectura segundo os princípios de Vignhola com um ensaio sobre as mesmas ordens feito sobre o sentimento dos mais célebres Architectos escriptas en Francez por ***e expostas em Portuguez por J.C.M.A. (...) enriquecida com 88 estampas abertas em cobre. tradução ao português por Antonio Barnicaud. Coimbra, 1787. Fonte: Setor de Microfilmes da Biblioteca Nacional de Portugal.

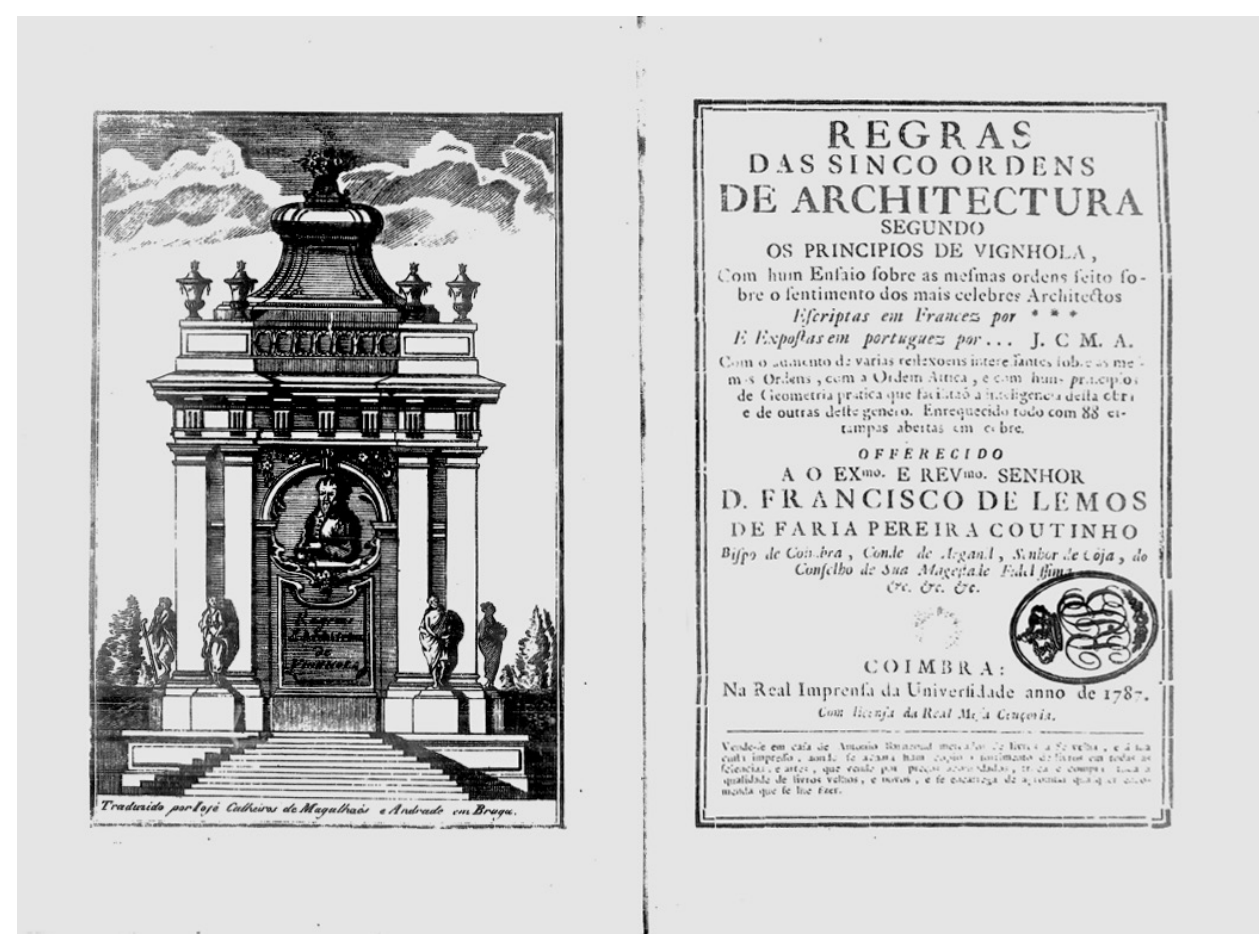

que o levou a empreender esta tradução foi, para além de responder ao pedido de alguns amigos que o solicitaram, o "gosto" de ver traduzido para "o nosso idioma Portuguez", evocando novamente a tônica que movera as edições de Vignola no século XVII, uma obra essencial aos que pretendem aprender arquitetura, "que he necessária aos Pintores, Emtalhadores, Armadores, Carpinteiros, e Canteiros", e ainda para todos os que pelas suas profissões, ou por curiosidade, necessitam aprender as regras desta arte. A escolha de Vignola deveu-se, segundo o autor da edição portuguesa, à "facilidade" com que expôs as cinco ordens, "tendo granjeado um sucesso ímpar nas principais cidades europeias" (BINHETI, 1787; MARQUES, 2014: 74-78).

O segundo livro editado em Portugal, no mesmo ano intitulava-se Regras das Sinco Ordens da Architectura segundo os princípios de Vignhola com um ensaio sobre as mesmas ordens feito sobre o sentimento dos mais célebres Architectos escriptas en Francez por ${ }^{* *}$ e expostas em Portuguez por J.C.M.A. (...) enriquecida com 88 estampas abertas em cobre (1787) [figura 5]. Sem revelar o autor da obra original em francês, a publicação saiu, em língua portuguesa, como de autoria identificada apenas pelas iniciais de J.C.M.A. Tratava-se de José Calheiros de Magalhães e Andrade (1789-1815), e tradução ao português por Antonio Barneaud, dedicado ao Bispo de Coimbra. José Calheiros de Magalhães e Andrade era natural de Braga, estudou Medicina em Coimbra e talvez também Matemática, matéria que teria lecionado na Academia Real de Marinha e Comércio da Cidade do Porto (MARQUES, 2014: 74-75).

As Regras das Sinco Ordens de Magalhães e Andrade faziam parte, certamente, de toda a história das edições e traduções de Vignola. No entanto, seguia mais diretamente 
90 alemão Raiville, sem completar seus estudos na Politécnica, seguiu o curso de Matemática em Hanover e Carlsruhe (sic). Transferiu-se ao Brasil e se naturalizou brasileiro, foi inspetor geral das obras públicas no Espírito Santo; nomeado engenheiro da Repartição Geral dos Telegraphos em Itabapoana e Caravellas e inaugrou a ligação telegráfica entre Vitória e Rio de Janeiro. O livro não foi dirigido aos arquitetos da Academia Imperial de Belas Artes, mas a construtores amadores. (ROCHA-PEIXOTO, 2006: 171-191).

10 "O Superego age como parte da estrutura da personalidade cultural do indivíduo, representando a construção de todos os valores sociais que foram absorvidos pela pessoa ao longo da vida (...). Todos os ideais internalizados e que formam o Superego são adquiridos através dos valores familiares particulares de cada indivíduo, assim como aqueles partilhados pela sociedade em que está inserido (...)" (HOMRI$\mathrm{CH}, 2008)$. uma estrutura expositiva e didática semelhante à do livro Jacques Barozzio de Vignole. Nouveau Livre, editado em Paris, por Jacques Cherreau, em 1747, com gravuras de Babel, mencionado explicitamente pelo autor português. Magalhães e Andrade (1787) afirmava, no prólogo, sua intenção, diante das edições de Vignola em outras línguas, de traduzir ao português e explicar de modo mais claro aos principiantes o cânone das Cinco Ordens, quando descobriu a edição francesa de Babel (1747), a qual já cumpria com seus propósitos. "No tempo em que eu meditava sobre o modo de por em execução o meu designio, apareceu-me um livro em francês (...) [ele cita Babel] e que a tradução desse livro satisfaria ao fim que me propunha" (JCMA, 1787: I-VII). Magalhães concluiu o prólogo, curiosamente, retomando as ideias reparadoras de uma ordem perdida pelos abusos de inveções dos séculos XVII e do próprio XVIII, como vimos em Giuseppe Ercolani. Magalhães Escreveu:

Eu tive cuidado de advertir os principiantes dos limites que deve ter a invenção do Arquiteto em compor segundo o seu gosto e variar os diferentes membros em cada ordem porque sobre isso tem havido um abuso notável que tem feito pôr em execução corpos desordenados e informes filhos unicamente da fantasia e contra as regras principais adotadas pelos melhores arquitetos desde os Gregos até os nossos tempos. (JCMA, 1787: I-VII)

Podemos afirmar que no século XVIII haveria uma renovação do interesse editorial pelos livros dedicados às Cinco Ordens. No entanto, as edições portuguesas não deixavam de dever a todo o conjunto secular de publicações sobre o tema, de um lado voltadas para os artesãos e, de outro, em especial no Setecentos, para a recuperação da "verdadeira arquitetura".

Em 1880 é publicado no Brasil, pelo autor alemão nacionalizado brasileiro, César Raiville, o livro O Vinhola Brazileiro - Novo Manual Prático do Engenheiro, Architecto, Pedreiro, Carpinteiro, Marceneiro e Serralheiro, pela Casa Editora Laemmerts do Rio de Janeiro". Introduzia sintomaticamente seu livro alegando que "tendo visto tantas edificação e obras mal feitas aqui pelas villas e roças, sem o conhecimento das regras mais simples, me pareceu necessário escrever alguma cousa ao alcance de todos (...)". Mais uma vez se fazia a evocação, ao mesmo tempo longeva e tardia, de Vignola, que parecia ter ainda, ao final do Oitocentos no Brasil, um poder regenador somado à facilitação de seus princípios e regras.

Pelo que se pode apreender das inúmeras edições de Vignola e adaptações com variadas interpretações de seu sentido desde o século XVI, ora como leitura de Corte e formação do olhar diletante da aristorcracia e dos "conhecedores" das artes de modo geral; ora como um livro "de arquitetos", voltado para o ambiente intelectual das Academias e finalmente como um elemento de recuperação da ordem perdida; ora como um livro aplicado à rotina dos artesãos, o conhecimento exigido para seus exames de ofício - portanto um saber aplicado ao fazer artesanal - Vignola se tornava ao longo dos séculos uma espécie de superego ${ }^{10}$, para usar um conceito freudiano; ou quem sabe um heterônimo, para emprestar um termo da literatura, cujo sentido de autor e de autoria ultrapassava os limites de sua individualidade e de seu tempo. 


\section{Referências bibliográficas}

ALPERS, Svetlana. El arte de describir. El arte holandés en el siglo XVII. Madrid: Hermann Blume, 1987.

BAROZZIO DA VIGNOLA, Giacomo. Reglas de las Cinco Ordenes de Arquitectura. Madrid: Colegio de Aparejadores, 1997.

BAROZZIO DA VIGNOLA, Giacomo. Regole delle Cinque Ordini dell'Architettura, 1562. Disponível em <http://architectura.cesr.univ-tours.fr/Traite/Images/LES64Index.asp>.

BINHETI, José Carlos. Regra das cinco ordes de Architectura de Jacomo Barocio de Vinhola traduzidas do seu original em nosso idioma com hum acrescentamento de Geometria Pratica, e Regras de Prespectiva de Fernando Gallibibiena. Lisboa, José de Aquino Bulhões, 1787.

BLONDEL, Jacques François. Livre Nouveau ou Règles des Cinq Ordres d'Architecture, Paris 1757.

BLUM, Hans. Von den Fünff Sülen Grundtlicher bericht vnnd deren eigentliche contrafeyung nach Symmestrischer vBteilung der Architectur .... Zürich, 1554.

BRANDÃO, Angela. Tratados de Arquitetura no Livro dos Regimentos: uma sutil referência. In Anais do XXXIV Colóquio do Comitê Brasileiro de História da Arte. Territórios da História da Arte. CBHA. Uberlândia, 2014. Pp. 429-436. Disponível em <http://www.cbha.art.br/ coloquios_anteriores.html>. Acesso em 4 de setembro de 2017.

BRANDÃO, Angela. Entre o saber e o fazer: Vredeman de Vries e os artesãos de ofícios no contexto luso-brasileiro do século XVIII. In Circumscribere 20 (2017): pp. 43-60. Disponível em https://revistas. pucsp.br/circumhc/article/view/35517. Acesso em 03 de outubro de 2019.

CARVAlHO, Ayres de. Catálogo da Colecção de Desenhos. Lisboa: Biblioteca Nacional de Lisboa, 1977.

CATFORD, John Cunnison. Uma teoria lingüística da tradução. São Paulo: Cultrix, 1980.

CORREIA, Vergílio. Livro dos Regimentos dos officiaes mecanicos da mui nobre e sëpre leal cidade de Lixboa -1572. Publicado e prefaciado pelo Dr. Vergílio Correia. Coimbra: Imprensa da Universidade, 1926.

D'AVILER, Charles. Cours d'Architecture qui comprend les Ordres de Vignole, Paris, 2vols, 1691.

DELAGARDETTE, Claude-Mathieu. Règles des Cinques Ordres de l'Architecture de Vignole. Disponível em <https://gallica.bnf.fr/ark:/12148/bpt6k6327303x/f11.image.texte>

DURANTE, Silvio. Jacques François Blondel. In Enciclopædia Biográfica de Arquitetos Digital. Documento n: B19. 2015. Disponível em https://www.ebad.info/blondel-jacques-franois. Acesso em 28 de janeiro de 2020.

ERCOLANI, Giuseppe Maria. I tre ordine d'architettura dorico, ionico e corintio presi dalle fabbriche più celebri dell'antica Roma. Roma: Antonio de Rossi, 1774.

HOMRICH, Adriana Chaves Borges. O Conceito de Superego na Teoria Freudiana, São Paulo: Universidade de São Paulo. Instituto de Psicologia, 2008. Disponível em <https://www. significados.com.br/superego/>, acesso em 18 de maio de 2019.

INDAU, Johann. Wiennerisches Architectur-Kunst und Säulen-Buch. Augsburg: Jeremias Wolff, 1722. Disponível em http://digi.ub.uni-heidelberg.de/diglit/idau1722/0005 Acesso em 06 de outubro de 2019.

J.C.M.A Regras das Sinco Ordens da Architectura segundo os princípios de Vignhola com um ensaio sobre as mesmas ordens feito sobre o sentimento dos mais célebres Architectos escriptas en Francez por ${ }^{* *}$ e expostas em Portuguez por J.C.M.A. (...) enriquecida com 88 estampas abertas em cobre. Tradução ao português por Antonio Barnicaud. Coimbra, 1787. 
LEEKE, John. Canon of the Five Orders of Architecture. Giacomo Barozzi da Vignola. New York, Dover, 2011.

LIVRO DOS REGIMENTOS DOS OFFICIAES MECANICOS DA MUI NOBRE E SËPRE LEAL CIDADE DE LIXBOA -1572. Publicado e prefaciado pelo Dr. Vergílio Correia. Coimbra: Imprensa da Universidade, 1926.

LOMBAERDE, Piet. Hans Vredemand de Vries and the Artes Machanicae revisited. 2005.

MAGNINO, Julius von Schlosser. La Letteratura Artistica. Milano: Paperback Classici, 2000.

MARQUES, Ana Luísa Santos. Arte, Ciência e História no Livro Português do Século XVIII. Doutoramento em Belas-Artes Especialidade de Ciências da Arte. Universidade de Lisboa, 2014. Disponível em <https://repositorio.ul.pt/bitstream/10451/19926/1/ulsd071070_td_ vol_1.pdf>. Acesso em 06 de outubro de 2019.

MOREIRA, Rafael e RODRIGUES, Ana Duarte. coord. Tratados de Arte em Portugal. Lisboa: Scribe, 2011.

RAIVILLE, César. O Vinhola brasileiro - novo manual prático do engenheiro, arquiteto, pedreiro, carpinteiro, marceneiro e serralheiro. Rio de Janeiro: Eduardo \& Henrique Laemmert, 1880.

REGIMENTO DO OFFICIO DE CARPINTEIRO DE MOVEIS E SEMBLAGE. Arquivo da Câmara de Lisboa. (REF. BL 2A 32.03.38).

REGRAS DAS SINCO ORDENS DA ARCHITECTURA segundo os princípios de Vignhola com um ensaio sobre as mesmas ordens feito sobre o sentimento dos mais célebres Architectos escriptas en Francez por $* * *$ e expostas em Portuguez por J.C.M.A. (...) enriquecida com 88 estampas abertas em cobre. Sem revelar o autor do livro em francês, a publicação tem autoria em língua portuguesa identificada apenas pelas inicias J.C.M.A. e tradução ao português de Antonio Barnicaud, dedicada ao Bispo de Coimbra e datada de 1787.

ROCHA-PEIXOTO, Gustavo. Tratados Brasileiros de Arquitetura do Século XIX. In MIZOGUSHI, MACHADO (org.) Palladio e o Neoclassicismo. Porto Alegre: EDIPUCRS, 2006

RYKWERT, Joseph. A Coluna Dançante: sobre a ordem na arquitetura. São Paulo: Perspectiva, 2015.

SILVA, Mônica Messias. Antiguidade da Arte da Pintura, sua nobreza, divino e humano que a exercitou, e honras que os monarcas fizeram a seus artífices Félix da Costa Meesen 1696 Texto Modernizado e Análises. Dissertação. Programa de Pós-Graduação "Culturas e Identidades Brasileiras". Instituto de Estudos Brasileiros (USP-São Paulo), Orientador: Prof. Dr. Luiz Armando Bagolin. São Paulo, 2018. Disponível em: https://teses.usp.br/ teses/disponiveis/31/31131/tde-01032018-130721/publico/Corrigida_MonicaSilva.pdf Acesso em 22 de outubro de 2019.

SOUZA, Jaime M. Mobiliário. In Dicionário da Arte Barroca em Portugal. Lisboa: Presença, 1989.

TOGNON, Marcos. Tratados de Arquitetura no Século XVIII para a Produção Artística Barroca: O Vinhola Português do Século XVIII. Conferência, Seminário Internacional de História da Arte - História e Ccultura, Gênero Artístico - Processo Artístico. Belo Horizonte.Volume: 1, 2014.

TOLEDO, Benedito Lima de. Do Século XVI ao início do Século XIX: maneirismo, barroco e rococó. (A obra de Serlio e Vignola e os Regimentos de Ofícios). In ZANINI, W. História Geral da Arte no Brasil. São Paulo: Instituto Walther Moreira Salles, 1983.

VIGNOLE (Jacques Barozzio de)] Règles des cinq ordres d architecture de Vignole. Edité par Chez F. Jollain, 1694

VIGNOLE, Jacques Barozzio de. NOUVEAU LIVRE. On y joint un essai sur les mêmes Ordres, suivant le sentiment des plus Célébres ARCHITECTES. Le tout enrichi de Vignettes et Cartels; dessinés Et Gravés par Babel. A Paris. Chez Jacques Cherreau. M.DCC.XLVII. [1747]. 
VREDEMAN DE VRIES, Hans (1527-ca 1606). Perspective. French text. Leyden and the Hague: Beuckel Nieulandt for Hendrik Hondius, 1604-1605. Disponível em Archive. https://archive. org/details/gri_33125009324910, acesso em 21 de agosto de 2017.

VREDEMAN DE VRIES, Hans. ARCHITECTURA, ou Bâtiment, pris de Vitruve et des anciens écrivains, Traitant sur les cing ordres des colonnes, dont on peut ordiner et approprier toutes sortes et pratiques des bâtiments, profitable pour tous maîtres de fabrique, maîtres maçons, menuisiers, charpentiers, tailleurs d'images et tous autres amateurs de l'art d'architecture, avec la déclaration des figures, de nouveau mises en lumière et inventées par Jean Vredeman. Disponível em Archive <https://archive.org/details/gri_33125009324910>, acesso em 21 de agosto de 2017 